\title{
Highly-Excited State Properties of Cumulenone Chlorides in the Vacuum-Ultraviolet ${ }^{\dagger}$
}

\begin{abstract}
Quynh L. D. Nguyen, ${ }^{* a}$ William K. Peters, ${ }^{a \ddagger}$ and Ryan C. Fortenberry ${ }^{b}$
Recent observations of chloromethane in interstellar environments suggest that other organohalogens, which are known to be critically important in Earth's atmosphere, may also be of significance beyond our own terrestrial veil. This raises the question of how such molecules behave under extreme conditions such as when exposed to vacuum ultraviolet (VUV) radiation. VUV photons promote molecules to highly excited states that fragment in non-statistical patterns controlled by the initial femtosecond dynamics. A detailed understanding of VUV-driven photochemistry in complex organic molecules that consist of more than one functional group is a particularly challenging task. This quantum chemical analysis reports the electronic states and ionization potentials up to the VUV range $(6-11 \mathrm{eV})$ of the chlorine-substituted cumulenone series molecules. The valence and Rydberg properties of lone-pair terminated, $\pi$-conjugated systems are explored for their potential resonance with lone pairs from elsewhere in the system. The carbon chain elongation within the family $\mathrm{ClHC}_{n} \mathrm{O}$, where $n=1-4$, influences the electronic excitations, associated wavefunctions, and ionization potentials of the molecules. The predicted geometries and ionization potentials are in good agreement with the available experimental photoelectron spectra for formyl chloride and chloroketene, $\mathrm{n}=1-2$. Furthermore, comparison between the regular cumulenone species and the corresponding chlorinated derivatives exhibit similar behaviors especially for $n=3$, where the allene backbone in propadienone chloride is severely bent. Most notably for the excited states is that the Rydberg character becomes more dominant as the energy increases, with some retaining valence characters.
\end{abstract}

\section{Introduction}

Most small molecules concentrate their oscillator strength in the vacuum ultraviolet (VUV) $\frac{1}{1}$, and a detailed knowledge of the corresponding excited states is critical to understanding photophysics and photochemistry in environments containing both appreciable VUV photon flux and significant molecular density. Such environments include circumstellar dust clouds, the upper portions of planetary atmospheres, and the immediate vicinity of high-energy transient phenomena such as lightning strikes or explosions 2 , 4. For example, on our own planet, incident VUV flux interacting with molecular flux from below influences the ionosphere-thermosphere coupling 5 . Additionally, in exoplanetary atmospheres, VUV-driven photochemistry can produce nonequilibrium chemical compositions that may otherwise be interpreted as biosignatures ${ }^{7}$. In protoplanetary disks, a deeper understanding of how complex molecules form in the presence of an overwhelming VUV photon flux is of critical importance to modeling the chemical composition of nascent planetary atmospheres 89 .

In small polyatomic molecules, the energy range from about 5 or $6 \mathrm{eV}$ up to the ionization threshold, roughly $10 \mathrm{eV}$, presents particular challenges both experimentally and theoretically 1011 .

\footnotetext{
a Department of Chemistry, University of Colorado Boulder. E-mail: Quynh.L.Nguyen@colorado.edu

${ }^{b}$ Department of Chemistry \& Biochemistry, University of Mississippi, University, $M S$ 38677-1848, U.S.A.

$\dagger$ Electronic Supplementary Information (ESI) available: Additional details of calculations and cartesian coordinates. . See DOI: 10.1039/cXCP00000x/

$\ddagger$ Present address: Los Alamos National Laboratory
}

In this energy range, molecules display both highly-excited valence states and low-lying Rydberg states, often strongly mixed with each other. These states generally lead to a cascade of non-statistical fragmentation with branching ratios dominated by early-time (femtosecond) dynamics. Detailed knowledge is hard to come by, however, as large densities of states and highly diffuse wavefunctions make ab initio calculations prohibitively expensive. Experimentally, the same large densities of states combine with short lifetimes to cause congested spectra that require nonlinear spectroscopic techniques to interrogate, but convenient and flexible laser sources have only recently become available.

Previous results, both experimental and theoretical, on initial femtosecond dynamics and their influence on the relaxation of VUV excited states have pointed toward a critical role played by Rydberg-valence mixing. Experiment and high level calculations on ethylene has indicated that the $\pi^{*} \leftarrow \pi$ quickly transfers to the $3 s$-Rydberg state within less than 10 fs through ultrafast internal conversion and then transfers back to the valence state within $60 \mathrm{fs} \frac{1213}{}$. Ultrafast photoelectron spectroscopy on the nitrogen-containing heterocycles pyrrole, N-methyl pyrrole, and 2,5-dimethyl pyrrole have indicated the $3 p$-Rydberg state is populated for tens of femtoseconds before Rydberg-valence mixing allows access to conical intersections that drive electronic relaxation 1415. Ultrafast photoelectron-photoion coincidence measurements combined with high-level calculations have revealed strong nonadiabatic behavior as well as Rydberg-valence mixing both play key roles in highly excited states of methyl azide, further emphasizing the difficulty of such studies 16 .

As more complex molecules are considered, there is an open question of what may happen when multiple Rydberg series built 
on different ionization centers are present. For example, in an organic molecule with two functional groups present, Rydberg series converging to ionization from the two different groups may both exist. Interestingly, a near-degeneracy between low- $n$ Rydberg states of different series would be quite common. Using typical quantum defects [ $\delta$ is about 1 for an $s$-wave and $\delta$ is about 0.5 for a $p$-wave $\mathrm{e}^{10[11}$, we would expect HOMO $\rightarrow 3 p$ and (HOMO1) $\rightarrow 3 s$ to be within a few tenths of an electronvolt anytime the first two ionization potentials are separated by $1-1.5 \mathrm{eV}$, which is a reasonably common situation for organic molecules 17 . In the presence of these near-degeneracies, we may expect significant mixing between different Rydberg series, either by directly coupling to each other (similar to hole-mixing or non-Koopman's effects in photoelectron spectra) or by both coupling to the same valence state. Indeed, exactly this sort of situation was observed in methyl azide ${ }^{16}$ where the excited state consisted of two diabatic Rydberg states and a diabatic valence state $\left(\pi^{n b} \rightarrow 3 p, \sigma_{C N} \rightarrow 3 s\right.$ and $\left.\sigma_{C N} \rightarrow \sigma^{*}\right)$. Such mixing has been noted in a few molecules, including $\mathrm{CO}, \mathrm{O}_{2}, \mathrm{~N}_{2}$, and $\mathrm{HN}_{3}$, but the phenomenon has not been extensively explored 18,21 .

Formyl chloride (ClCHO) - a derivative of formaldehyde with a hydrogen replaced by chlorine-presents a potential prototype for VUV photophysics in the presence of two Rydberg series. It contains two distinguishable ionization centers-lone pairs on the oxygen atom and those on the chlorine atom-that appear relatively localized in the photoelectron spectra ${ }^{22}$ but whose Rydberg states are likely to appear in near-degeneracies. Furthermore, the species is known to play an important role in terrestrial photochemistry 23 and due to recent observations of chloroalkanes in the interstellar medium ${ }^{28 \mid 32}$ may be expected to exist in a variety of astrochemical settings, indicating that its VUV excited states are not merely of theoretical interest.

In Earth's atmosphere, ClHCO is a relatively transient molecule that has been the subject of many high resolution infrared and microwave spectroscopic studies due to its significant contributions to tropospheric and stratospheric pollution 23 . It is typically observed under tropospheric conditions as a major product of reactions between chlorinated species with volatile organic compounds-isoprene with $\mathrm{Cl}$ atoms ${ }^{24}, \mathrm{H}_{2} \mathrm{O}$ radical with $\mathrm{CHCl}_{2} \mathrm{O}^{2526}$, and $\mathrm{OH}$ radical with vinyl chloride or trichloroethene 27 . Additionally, formyl choride is either a major product or an intermediate in atmospheric breakdowns of Cl-bearing hydrocarbons that are, in turn, major players in the degradation of the ozone layer. From here, theory predicts that $\mathrm{ClCHO}$ can dissociate via $\mathrm{Cl}-\mathrm{C}$ bond cleavage via the internal conversion or intersystem crossing from the lowest singlet and triplet states 33 . It may also reacts with $\mathrm{H}$ radicals to either produce $\mathrm{Cl} \dot{\mathrm{CO}}+\mathrm{H}_{2}$ or $\mathrm{Cl} \dot{\mathrm{CO}}+\mathrm{HCl}$, where the hydrogen abstraction channel dominates 23 . Some of these are among the most dominant and reactive species in the atmosphere, and thus, understanding the photophysical properties of formal chloride could potentially yield insights in pollutant mitigation within the ozone layer.

Considering the abundance of extended linear chains that have been detected in interstellar and circumstellar environments 34 , whe extend our analysis from formyl chloride to longer cumulenone chlorides. Although these species have not yet been detected, the non-chlorinated cumulenene ketone species-formaldehyde $\left(\mathrm{H}_{2} \mathrm{CO}\right)$, ketene $\left(\mathrm{H}_{2} \mathrm{C}=\mathrm{C}=\mathrm{O}\right)$, propadienone $\left(\mathrm{H}_{2} \mathrm{C}=\mathrm{C}=\mathrm{C}=\mathrm{O}\right)$, and their corresponding radicals post hydrogen cleavage $\left(\mathrm{HC}_{\mathrm{n}} \mathrm{O}\right)$-have been detected in the atmosphere ${ }^{38 / 39}$ and interstellar clouds 40 42. The dehalogenated radicals of these species have also been discovered in laboratory settings with some also observed in the ISM, suggesting that reactions similar to those of formyl chloride are certainly possible in similar conditions $43 / 44$. These cumulene neutrals and radicals are bathed in a chlorine environment, which may eventually lead to the formation of chlorinated cumulenones via

$$
\dot{\mathrm{H}}_{\mathrm{n}} \mathrm{O}+\mathrm{Cl}_{2} \rightarrow \mathrm{ClHC}_{\mathrm{n}} \mathrm{O}+\mathrm{Cl}
$$

Following the same scheme, $\mathrm{ClHCO}$ and $\mathrm{Cl}$ have been produced exclusively with no byproducts, where formaldehyde radicals, $\mathrm{HC} \mathrm{C}$, were generated via photolysis $43 / 45 \mid 46$.
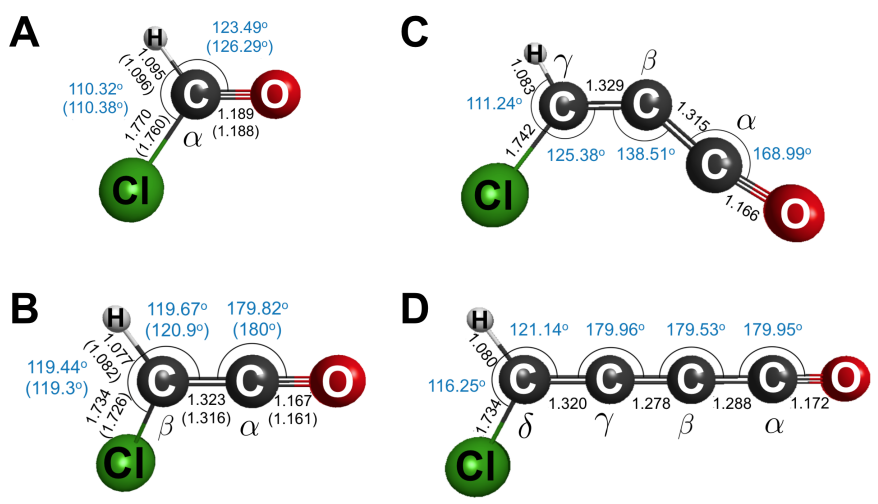

Fig. 1 Calculated neutral ground state geometries of cumulenone chlorides: Geometry optimizations are done at $\operatorname{CCSD}(\mathrm{T}) / \mathrm{d}$-aug-cc$\mathrm{pV}(\mathrm{T}+\mathrm{d}) \mathrm{Z}$ for $(\mathrm{A})$ formyl chloride, $(\mathrm{B})$ chloroketene, (C) propadienone chloride, and (D) butatrienone chloride. Corresponding microwave spectroscopic measurements are shown in parentheses for $(A)$ and $(B) .47 / 48$

Beyond our own atmosphere on Earth, chlorinated organics have been observed on Mars by the Viking and Curiosity landers 2829 , and also the interstellar medium (ISM) 30 . Particularly, haloalkanes have recently been detected in star-forming regions where the UV photon flux is relatively high. Most notably, chloromethane recently became the first Cl-bearing organohalogen reported in the triple protostar system IRAS 16293-2422 where photochemistry is highly likely to influence the surrounding chemistry 49 . In environments with both chloroalkanes and oxidizing species, such as Martian soil, we may suspect similar chemistry as that observed in Earth's atmosphere, including the possible presence of formyl chloride $28|29| 50$.

In this paper, we calculate ground state geometry, vertical and adiabatic ionization energies, and vertical excitation energies including in the VUV region for formyl chloride. We extend the analysis on $\mathrm{ClCHO}$ to its related species with elongated allene chains: chloroketene $\left(\mathrm{ClHC}=\mathrm{C}=\mathrm{O}, \mathrm{ClHC}_{2} \mathrm{O}\right)$, propadienone chloride $\left(\mathrm{ClHC}=\mathrm{C}=\mathrm{C}=\mathrm{O}, \mathrm{ClHC}_{3} \mathrm{O}\right)$, and butatrienone chloride ( $\mathrm{ClHC}=\mathrm{C}=\mathrm{C}=\mathrm{C}=\mathrm{O}, \mathrm{ClHC}_{4} \mathrm{O}$ ). We compare our predicted geometries and excited state properties to experimental data in cases where measurements are available. Our findings represent an 
Table 1 Theoretical bond lengths $(\AA)$ and angles $\left({ }^{\circ}\right)$ of the cumulenone chlorides optimized at $\operatorname{CCSD}(\mathrm{T}) / \mathrm{d}$-aug-cc-pV(T+d)Z). The corresponding microwave experimental measurements $47 / 48$ are reported in parentheses underneath.

\begin{tabular}{|c|c|c|c|c|c|c|c|c|c|c|}
\hline & $r_{C C l}$ & $r_{C H}$ & $r_{C O}$ & $r_{C_{\alpha \beta}}$ & $r_{C_{\beta \gamma}}$ & $\overline{r_{C_{\gamma \delta}}}$ & $\theta_{\mathrm{ClCC} / \mathrm{ClCO}}$ & $\theta_{\mathrm{HCCl}}$ & $\bar{\theta}_{O C C}$ & $\theta_{C_{\alpha \beta \gamma}}$ \\
\hline$\overline{\mathrm{ClHCO}}$ & $\begin{array}{c}1.770 \\
(1.760)\end{array}$ & $\begin{array}{c}1.095 \\
(1.096)\end{array}$ & $\begin{array}{c}1.189 \\
(1.188)\end{array}$ & & & & $\begin{array}{l}123.490 \\
(126.29)\end{array}$ & $\begin{array}{l}110.318 \\
(110.38)\end{array}$ & & \\
\hline $\mathrm{ClHC}_{2} \mathrm{O}$ & $\begin{array}{c}1.734 \\
(1.726)\end{array}$ & $\begin{array}{c}1.077 \\
(1.082)\end{array}$ & $\begin{array}{c}1.167 \\
(1.161)\end{array}$ & $\begin{array}{c}1.323 \\
(1.316)\end{array}$ & & & $\begin{array}{l}119.674 \\
(120.9)\end{array}$ & $\begin{array}{c}119.436 \\
(119.3)\end{array}$ & $\begin{array}{c}179.819 \\
(180)\end{array}$ & \\
\hline $\mathrm{ClHC}_{3} \mathrm{O}$ & 1.742 & 1.083 & 1.166 & 1.315 & 1.329 & & 125.382 & 111.244 & 168.992 & 138.508 \\
\hline $\mathrm{ClHC}_{4} \mathrm{O}$ & 1.734 & 1.080 & 1.172 & 1.288 & 1.278 & 1.320 & 121.142 & 116.253 & 179.948 & 179.530 \\
\hline
\end{tabular}

important step toward understanding the interaction between different functional groups in VUV-induced photophysics and photochemistry of complex molecules, which is already strikingly nonstatistical even in simpler molecules.

\section{Computational Methods}

The CFOUR ${ }^{51}$ and PSI4 ${ }^{52}$ computational packages are employed for all calculations with several correlation consistent basis sets 53 . The ground state neutral geometries are optimized through density functional theory (DFT) with the B3LYP functionals $54 \mid 55$, second-order Moller-Plesset perturbation theory (MP2) $\sqrt[56]{\text {, and }}$ coupled cluster theory at the singles, doubles, and perturbative triples $(\operatorname{CCSD}(\mathrm{T}))^{57}$ levels of theory with the d-aug-cc$\mathrm{pV}(\mathrm{T}+\mathrm{d}) \mathrm{Z}^{58}$ basis set. All minima are confirmed with harmonic vibrational analysis at the corresponding levels of theory, which yield all real frequencies. $\mathrm{ClHC}_{4} \mathrm{O}$ geometry optimized at the $\operatorname{CCSD}(\mathrm{T})$ level, however, yields one imaginary frequency that will be discussed later. Vertical (VIE) and adiabatic (AIE) ionization energy calculations of all species are computed via equation of motion - ionization potential - coupled cluster singles and doubles (EOMIP-CCSD) 59 with the aug-cc-pVTZ and d-aug-ccpVTZ basis functions. The AIEs for $\mathrm{ClHCO}, \mathrm{ClHC}_{2} \mathrm{O}$, and $\mathrm{ClHC}_{3} \mathrm{O}$ are also computed with the d-aug-cc-pV(T+d)Z basis.

Vertical excitation energies are calculated at the EOMCCSD 6263 level with multiple basis sets, including correlation consistent and Ahldrich's basis sets $64 \mid 65$. Extra diffuse functions are added to the d-aug-cc-pV(T+d)Z and t-aug-cc-pV(T+d)Z implemented in PSI4 in an even-tempered manner used previously for excessively diffuse basis sets of anions 66 . These bases are used for all single point calculations to fully account for the diffuseness of the electron density in potentially highly-diffuse states around the molecule. Additionally, since the computational cost scales up with the size of the molecule, a set of $6 s, 6 p, 2 d$ diffuse functions located about the center-of-mass are utilized in conjunction with the aug-cc-pVDZ and aug-cc-pVTZ basis sets to compute the excited state properties of all four systems 68 [0|71 and are written in shorthand as $\mathrm{DZ}+$ spd and $\mathrm{TZ}+$ spd.

In order to characterize the excited states, a MATLAB script is written to take linear combinations of virtual t-aug-cc-pV(T+d)Z molecular orbitals that participate in the transition with the coefficients given by EOM-CCSD calculations. A python script is used in complement with VMD1.9.3 to visualize the transition orbitals for each excited state 5272 . A complete set of excited state orbitals for each molecule can be found in the supplementary information (SI).

\section{Results and discussion}

\subsection{Ground State Equilibrium Geometries}

A $\mathrm{CHCl}$ capping group breaks the symmetry of the cumulenic chain and yields a $\mathrm{Cs}$ symmetry for all the Cl-cumulenone molecules analyzed in this study. In these species, the $\pi_{C O}$ orbital is in-the-plane with the $\mathrm{CHCl}$ group for the even $n$ and is out-of-plane for the odd $n$ species. While $\mathrm{n}=1-2$ have been reported in a few microwave spectroscopic studies, $n=3-4$ have not been explored. The CCSD $(\mathrm{T}) / \mathrm{d}$-aug-cc-pV $(\mathrm{T}+\mathrm{d}) \mathrm{Z}$ ground state equilibrium geometries of $\mathrm{ClHCO}$ and $\mathrm{ClHC}_{2} \mathrm{O}$ compare well to the corresponding microwave spectroscopic measurements (Table 1 and Figure 1, 47/48. The computed and measured bond lengths agree to better than $0.01 \AA$ for $\mathrm{ClHCO}$ and $0.008 \AA$ for $\mathrm{ClHC}_{2} \mathrm{O}$, with $r_{\mathrm{CCl}}$ relatively yielding the largest discrepancies in both molecules. Theory and experiment are in better agreement for the bond angles of $\mathrm{ClHC}_{2} \mathrm{O}$ than $\mathrm{ClHCO}$ with discrepancies being less than $0.14^{\circ}$. While a similar difference is shown for $\mathrm{ClHCO}, \theta_{\mathrm{HCO}}$ is an exception as the reported value is $2.80^{\circ}$ higher than predicted at $123.490^{\circ}$.

Table 1 shows slight overall variations between the bond lengths and angles across the four systems, but there appear to be no particular patterns displayed in correlation with the carbon chain elongation. Although $\mathrm{ClHC}_{3} \mathrm{O}$ and $\mathrm{ClHC}_{4} \mathrm{O}$ geometries are not in the literature, the corresponding cumulene ketones have been reported. Notable differences are shown for $\theta_{O C C}$ and $\theta_{C_{\alpha \beta \gamma}}$ in $\mathrm{ClHC}_{3} \mathrm{O}$ as compared to the rest of the series, where the angles are $168.992^{\circ}$ and $138.508^{\circ}$, respectively. This indicates a pronounced bending at $\mathrm{C}_{\beta}$, where this bend is defined in Figure 1. and another nonlinearity at $\mathrm{C}_{\alpha}$ leading to the oxygen atom. The large deviations from linearity in the carbon chain is also reported for propadienone by previous experimental studies with $\theta_{O C C}=144.5^{\circ}$ and $\theta_{C_{\alpha \beta \gamma}}=169.4^{\circ} 7374$.

The even $n$ molecules, $\mathrm{ClHC}_{2} \mathrm{O}$ and $\mathrm{ClHC}_{4} \mathrm{O}$, exhibit linearity in the plane (Figure 1). Unlike propadienone, the structure of butatrienone remains controversial as nonlinearity is predicted in some studies while others suggest linearity in the cumulenic chain $75 \sqrt{76}$. This present study predicts a slight favor towards the Cs symmetry with a minor bend on $\mathrm{C}_{\beta}$ out-of-plane for $\mathrm{ClHC}_{4} \mathrm{O}$. This might be due to its floppy backbone with an anomolous low stretching frequency within the range of $54-139 \mathrm{~cm}^{-1}$, depending on the levels of theory employed. This behavior will be discussed later on in the section.

In any case, the replacement of $\mathrm{H}$ by $\mathrm{Cl}$ overall yields little effect on the ground state structure of the cumulenic chains as the odd and even $n$ both qualitatively resemble the corresponding cu- 
A

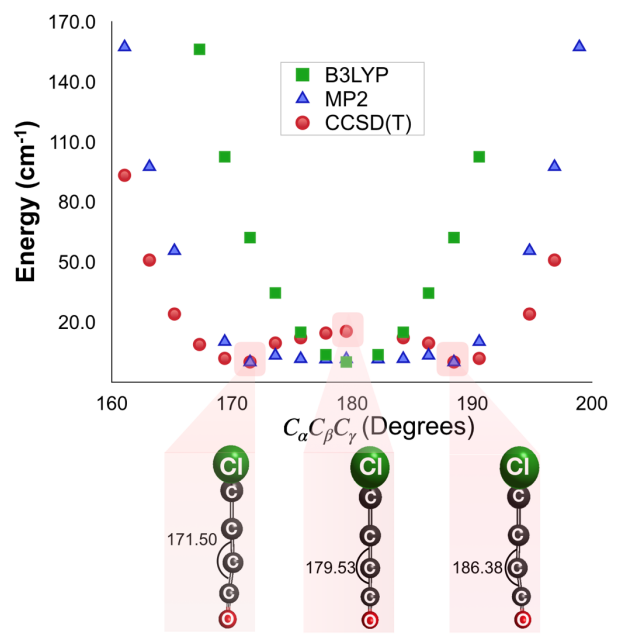

B

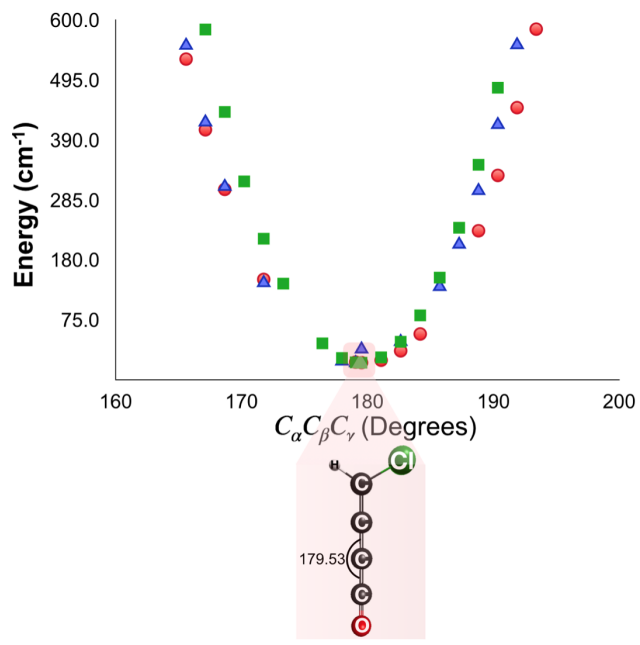

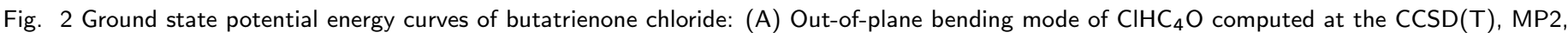

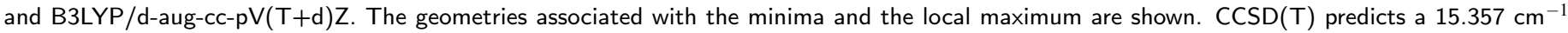

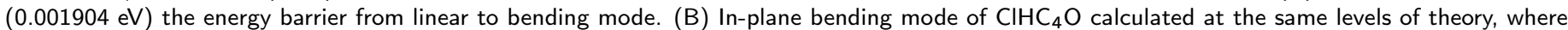

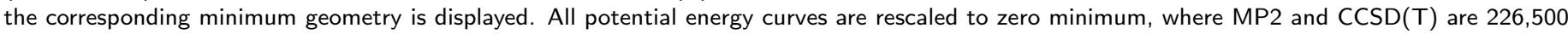
and $224,253 \mathrm{~cm}^{-1}$ above B3LYP, respectively.

mulenones. Such behavior is likely due to the minor contribution from $\mathrm{Cl}$ to the $\pi$-conjugation and, as such, leads to a small influence to the system. As a result, the oxygen lone-pairs dictate the nature of the backbone as seen in the case of $\mathrm{CH}_{2} \mathrm{O}$. Finally, the bending in both cases occur at $\mathrm{C}_{\beta}$, owing to the alternating triple-single-bond resonance structures where the oxygen lonepair donates and creates a triple bond on $\mathrm{C}_{\alpha}$ and a lone-pair on $\mathrm{C}_{\beta}$.

As compared to chloroketene, a pronounced bending on the beta carbon of propadienone chloride is predicted, indicating that the carbene character plays a more dominant role. On the other hand, propadienone has been known for its peculiar structure where an in-plane nonlinearity is observed in the allylic carbon chain 77 . Despite being the most abundant species observed experimentally relative to the other two $\left[\mathrm{H}_{2}, \mathrm{C}_{3}, \mathrm{O}\right]$ isomerscyclopropenone $\left(c-\mathrm{C}_{3} \mathrm{H}_{2} \mathrm{O}\right)$ and propynal ( $\mathrm{HCCCHO}$ - its detection is only limited to the laboratory 74 . This could simply be due to a lack of interstellar data for its spectral signatures. The experimental structure of propadienone has been determined based on ground state microwave spectra of its various isotopes, where pronounced bending is reported for $C_{\alpha}$ and $C_{\beta}$ with $\theta_{C_{\beta} C_{\alpha} O}$ $=169.4^{\circ}$ and $\theta_{C_{\alpha} C_{\beta} C_{\gamma}}=144.5^{\circ}$. These measurements are confirmed with $a b$ inito studies, varying from single-reference approaches such as B3LYP and the MP perturbation series to multireference approaches including QCISD and CASSCF 77/78. Similar results are also found for its radical, HCCCO, where the nonlinearity is experimentally observed for $C_{\alpha}$ and $C_{\beta}$, with angles $163^{\circ}$ and $136.5^{\circ}$, respectively 44 . As mentioned above, the structure of $\mathrm{ClHC}_{3} \mathrm{O}$ qualitatively resembles propadienone and its radical, where the molecule is nonlinear at $C_{\alpha}$ and $C_{\beta}$ with $\theta_{C_{\beta} C_{\alpha} O}$ $=169.0^{\circ}$ and $\theta_{C_{\gamma} C_{\beta} C_{\alpha}}=138.5^{\circ}$. Additionally, $\theta_{H C C l}$ of $\mathrm{ClHC}_{3} \mathrm{O}$ is $11^{\circ}$ less than $\theta_{\mathrm{HCH}}$ of propadienone, which results from the high electron density surrounding $\mathrm{Cl}$ that hinders it from the oxy- gen atom as well as the cumulenic chain. The peculiar structure of $\mathrm{ClHC}_{3} \mathrm{O}$ arises likely due to the delocalization of the in-plane $\pi$ conjugation on $C_{\beta}$ as has been observed for propadienone 73 . The electronic structure maintains the number of in-plane bonding orbitals between $\mathrm{ClHC}_{2} \mathrm{O}$ and $\mathrm{ClHC}_{3} \mathrm{O}$, but the relocation of the oxygen atom destabilizes the longer chain structure.

While propadienone posseses an in-plane nonlinearity, butatrienone is known to exist in competing symmetries of $C_{2 v}$ and $C_{S}$ with both in-plane and out-of-plane bending at $C_{\beta}$. However, studies by microwave spectroscopy and IR Argon matrix analysis conclude that $C_{2 v}$ is the dominant form 75 . The barrier between the linear and nonlinear geometries is approximately $0.0184 \mathrm{eV}$ $\left(148.4 \mathrm{~cm}^{-1}\right)$ theoretically and $0.00521 \mathrm{eV}\left(42 \mathrm{~cm}^{-1}\right)$ experimentally $76 / 80$. The energy barrier from $C_{s}$ and $C_{2 v}$ is evidently less than the Boltzmann factor at room temperature, $0.024 \mathrm{eV}$, allowing both configurations to be populated at ambient temperature. MP3/6-31G** suggests that this molecule has a flat potential along the carbon backbone for the out-of-plane bent geometry that results from the molecule undergoing large amplitude motions 80 . A recent study also shows that MP2/cc-pVTZ favors the $C_{S}$, while the DFT methods and CCSD/cc-pVTZ prefer the $C_{2 v}$ symmetry 81 .

Here, the $\operatorname{CCSD}(\mathrm{T}) / \mathrm{d}$-aug-cc-pV(T+d)Z linear ground state equilibrium geometry for $\mathrm{ClHC}_{4} \mathrm{O}$ yields an imaginary harmonic vibrational frequency corresponding to an out-of-plane bending mode at $77.6 \mathrm{~cm}^{-1}$. B3LYP and MP2 computations, using the same basis set, yield a linear geometry for the lowest energy configuration that are confirmed with harmonic vibrational analyses with all real frequencies. The same out-of-plane bending frequency is computed by B3LYP and MP2 to be $65.1 \mathrm{~cm}^{-1}$ and 138.9 $\mathrm{cm}^{-1}$, respectively. Such low stretching frequencies are indicative of the soft backbone in Cl-butatrienone that potentially allows it to interchange between nonlinearity and linearity. 
Table 2 Vertical and (adiabatic) ionization energies $(\mathrm{eV})$ of cumulenone chlorides with the corresponding newly creating singly-occupied orbital assignment computed at EOM-IP-CCSD level with aug-cc-pV $(T+d) Z$ basis set in comparison with experiment 2279. Vertical ionization energy calculated with $d$-aug-cc-pV $(T+d) Z$ basis set are shown in the $\mathrm{SI}$.

\begin{tabular}{|c|c|c|c|c|c|c|c|c|c|}
\hline \multicolumn{3}{|c|}{$\mathrm{ClHC}=\mathrm{O}$} & \multicolumn{3}{|c|}{$\mathrm{ClHC}=\mathrm{C}=\mathrm{O}$} & \multicolumn{2}{|c|}{$\mathrm{ClHC}=\mathrm{C}=\mathrm{C}=\mathrm{O}$} & \multicolumn{2}{|c|}{$\mathrm{ClHC}=\mathrm{C}=\mathrm{C}=\mathrm{C}=\mathrm{O}$} \\
\hline$\overline{\text { Sym }}$ & Theor & Expt & Sym & Theor & Expt & Sym & Theor & Sym & Theor \\
\hline$\overline{13 a^{\prime}}$ & $\begin{array}{l}11.673 \\
(11.498)\end{array}$ & $\begin{array}{l}11.61 \pm 0.01 \\
(11.51 \pm 0.01)\end{array}$ & $4 a^{\prime \prime}$ & $\begin{array}{l}9.477 \\
(8.938)\end{array}$ & $\begin{array}{l}9.30 \pm 0.05 \\
(9.11 \pm 0.03)\end{array}$ & $19 a^{\prime}$ & 9.735 & $5 a^{\prime \prime}$ & 8.735 \\
\hline $3 a^{\prime \prime}$ & 12.505 & $12.38 \pm 0.03$ & $15 a^{\prime}$ & 12.261 & $12.20 \pm 0.03$ & $18 \mathrm{a}^{\prime}$ & 10.782 & $20 a^{\prime}$ & 11.536 \\
\hline $12 \mathrm{a}^{\prime}$ & 12.531 & $12.46 \pm 0.03$ & $3 a^{\prime \prime}$ & 13.244 & $13.19 \pm 0.03$ & $4 a^{\prime \prime}$ & 12.229 & $4 a^{\prime \prime}$ & 11.885 \\
\hline $2 a^{\prime \prime}$ & 15.712 & $15.28 \pm 0.01$ & $14 \mathrm{a}^{\prime}$ & 14.854 & $14.70 \pm 0.05$ & $17 a^{\prime}$ & 13.639 & $19 \mathrm{a}^{\prime}$ & 12.008 \\
\hline
\end{tabular}

In an attempt to explain this behavior, electronic ground state potential energy surfaces (PES) are computed with the d-aug-cc$\mathrm{pV}(\mathrm{T}+\mathrm{d}) \mathrm{Z}$ basis set at the $\operatorname{CCSD}(\mathrm{T}), \mathrm{MP} 2$, and B3LYP levels of theory. The energies are calculated as a function of the $\theta_{C_{\alpha \beta \gamma}}$ using the $\operatorname{CCSD}(\mathrm{T})$ optimized geometry, where the bond angle is varied out-of-plane around its linearity at $180^{\circ}$ with steps of $1.5^{\circ}$ (Figure 2). As observed in regular butatrienone, the energy barriers between the two configurations calculated at $\operatorname{CCSD}(\mathrm{T})$ and MP2 are relatively small, $0.001904 \mathrm{eV}\left(15.65 \mathrm{~cm}^{-1}\right)$ and $0.000192 \mathrm{eV}$ $\left(15.46 \mathrm{~cm}^{-1}\right)$, respectively. B3LYP, however, misses the barrier and predicts linearity to be the optimum configuration. The left panel of Figure 2 shows that $\mathrm{ClHC}_{4} \mathrm{O}$ undergoes large amplitude motions, which result in a double well or a flat potential energy surface as predicted in butatrienone. Regardless, the marginal energy differences indicate that $\mathrm{ClHC}_{4} \mathrm{O}$ essentially interchanges between the linear and the out-of-plane $\mathrm{C}_{s}$ configurations even at most interstellar temperatures above $20 \mathrm{~K}$.

\subsection{Ionization Energies}

The vertical ionization energies (VIE) computed with the two basis sets, aug-cc-pVTZ and d-aug-cc-pVTZ, agree to $0.003 \mathrm{eV}$, indicating the diffuseness of the basis set beyond such a level does not influence the VIEs for the systems since these are pure valence structures (Table 2). In $\mathrm{ClHCO}$, the lowest IE corresponds to the removal of an electron from the oxygen lone pair $\left(n_{\mathrm{O}}\right)$, followed by the chlorine lone pairs from out-of-plane $\left(n_{\mathrm{Cl}}\left(a^{\prime \prime}\right)\right)$ and in-plane $\left(n_{\mathrm{Cl}}\left(a^{\prime}\right)\right)$, and the $\pi$ orbital $\left(n_{\pi}\right)$ (Table 2$)$. The two molecular planes are denoted as $a^{\prime}$ and $a^{\prime \prime}$ for in-plane and out-of-plane, respectively.

For formyl chloride, the lowest VIE, $11.673 \mathrm{eV}$, is $0.175 \mathrm{eV}$ higher than the AIE optimized at the same level of theory, 11.498 $\mathrm{eV}$. Both calculated values are in good agreement with the corresponding experimental measurements with 0.06 and $0.01 \mathrm{eV}$ discrepancies for vertical and adiabatic transitions, respectively 22 . The IE $n_{\mathrm{O}}$ of $\mathrm{ClHCO}$ is slightly higher than formic acid ( $\left.\mathrm{HCOOH}\right)$ and formaldehyde ( $\mathrm{HCOH}), 11.33$ and $10.88 \mathrm{eV}$, respectively 82 . The change in IE with respect to functional group substitution is therefore on the order of $\mathrm{Cl}>\mathrm{OH}>\mathrm{H}$. The exhibited pattern is due to the anti-correlation between the amount of energy required for electron removal and the stability of the cation formed post-ionization with respect to the neutral. Evidently, the replacement of $\mathrm{H}$ by the more electronegative $\mathrm{Cl}$ destabilizes the cation and increases the IE.

A larger difference, $0.5 \mathrm{eV}$, between the lowest VIE and AIE is predicted for $\mathrm{ClHC}_{2} \mathrm{O}$. Table 2 shows that the calculated VIEs are comparable with experimental measurements with differences varying between 0.05 to $0.17 \mathrm{eV} 79$. The IE $n_{\mathrm{O}}$ drops by about $2.3 \mathrm{eV}$ in $\mathrm{ClHC}_{2} \mathrm{O}$ as compared to $\mathrm{ClHCO}$, which is likely due to an elongation of the carbon-chain backbone enabling delocalization of the electron hole along the extended carbon chain, from $\mathrm{O}$ to $\mathrm{C}_{\beta}$. The extension in the cumulenic chain also results in the second ionization to originate from the $\mathrm{Cl}$ lone-pair in the $a^{\prime}$ plane instead of $a^{\prime \prime}$ as in ClHCO.

With the exception of the first ionization, all of the successive ionizations for $\mathrm{ClHC}_{3} \mathrm{O}$ cost less energy than those computed for $\mathrm{ClHC}_{2} \mathrm{O}$. On the other hand, the cation of $\mathrm{ClHC}_{4} \mathrm{O}$ is further stabilized with respect to the parent neutral. The first ionization potential occurs at $8.735 \mathrm{eV}$, which is about $1 \mathrm{eV}$ less than that of $\mathrm{ClHC}_{3} \mathrm{O}$. The elongation of the carbon chain again lowers the energy of the cation by enabling delocalization of the electron hole post ionization for even $n$ molecules.

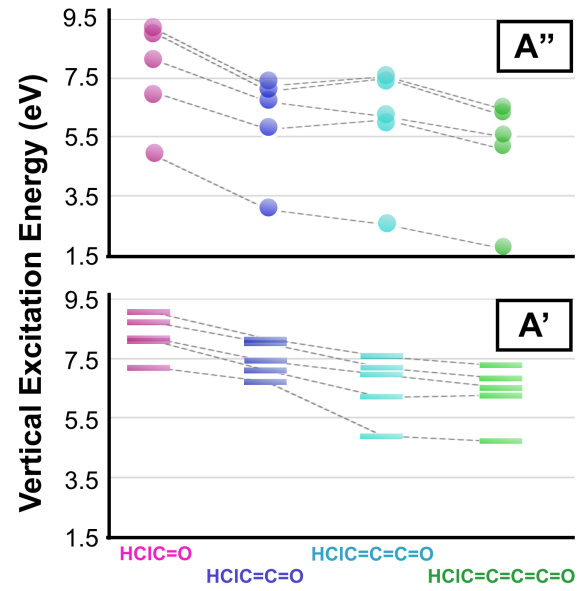

Fig. 3 Excited state properties of cumulenone chlorides: Vertical excitation energies with the corresponding characters of formyl chloride, chloroketene propadienone chloride, and butatrieneone computed at the EOM-CCSD/d-augcc-pV( $\mathrm{T}+\mathrm{d}) \mathrm{Z}$ level for the (top) out-of-plane and the (bottom) in-plane transitions.

\subsection{Vertical Excitation Energies}

Small chlorinated molecules, such as chloromethane and hydrogen chloride, are used to benchmark the adequacy of the $\mathrm{Cl}$ atom treatment in EOM-CCSD with different basis sets. The results are shown in Tables $13 \& 14$ in the SI. The excited state energies agree with the experimental measurements to within 0.1 $0.15 \mathrm{eV}$ of experiment $83 \mid 84$, which supports the claim that this 
method is an appropriate choice. Moreover, the $\mathrm{T}_{1}$ diagnostic confirms that EOM-CCSD provides adequate predictions for the excited states and multi-reference dynamical treatments are not necessary. $\mathrm{T}_{1}$ diagnostics are less than 0.02 for all species and particularly 0.016 for formyl chloride, which satisfies the typical multi-reference character, 0.02 , limit 85 . The + spd technique 6870 also produces results that are comparable to those of the d- and t-aug-cc-pV(T+d)Z for the CCSD(T), B3LYP, and MP2 optimized geometries (refer to Tables 19, 22, 25 in the SI) indicating that its usage is also proper when necessary.

Table 3 Excited state energies of cumulenone chlorides computed at EOM-CCSD level using ground state equilibrium geometries optimized at $\operatorname{CCSD}(T) / d$-aug-cc-pV $(T+d) Z$ with Dunning's basis sets where SA is the state assignment, $\mathrm{E}$ is the vertical excitation energy in $\mathrm{eV}$ and $f$ is the oscillator strength. The last two columns report the energies and oscillator strengths computed with t-aug-cc-pV(T+d)Z for $\mathrm{ClHCO}$ and $\mathrm{ClHC}_{2} \mathrm{O}$ and aug-cc-pVTZ+spd for $\mathrm{ClHC}_{3} \mathrm{O}$ and $\mathrm{ClHC}_{4} \mathrm{O}$.

\begin{tabular}{|c|c|c|c|c|c|c|}
\hline \multirow[t]{2}{*}{$\overline{\overline{\mathrm{SA}}}$} & \multicolumn{2}{|c|}{$\begin{array}{cc}E & f \\
\text { aug-cc-pV(T+d)Z }\end{array}$} & \multirow{2}{*}{\multicolumn{2}{|c|}{$\begin{array}{cc}E & f \\
\text { d-aug-cc-pV(T+d)Z } \\
\text { HClC }=\mathrm{O}\end{array}$}} & \multicolumn{2}{|c|}{$\begin{array}{cc}E & f \\
\text { t-aug-cc-pV(T+d)Z }\end{array}$} \\
\hline & & & & & & \\
\hline $1{ }^{1} A^{\prime \prime}$ & 4.963 & 0.1824 & 4.951 & 0.0001 & 4.951 & 0.0001 \\
\hline $2{ }^{1} A^{\prime \prime}$ & 7.091 & 0.2606 & 7.069 & 0.0003 & 7.069 & 0.0003 \\
\hline $1^{1} A^{\prime}$ & 7.245 & 0.2663 & 7.216 & 0.0191 & 7.216 & 0.0191 \\
\hline $2{ }^{1} A^{\prime}$ & \multicolumn{5}{|c|}{$\mathrm{HClC}=\mathrm{C}=\mathrm{O}$} & 0.0618 \\
\hline $1{ }^{1} A^{\prime \prime}$ & 3.057 & 0.0000 & 3.057 & 0.0000 & 3.057 & 0.0000 \\
\hline $2{ }^{1} A^{\prime \prime}$ & 5.759 & 0.0043 & 5.749 & 0.0040 & 5.749 & 0.0040 \\
\hline $3{ }^{1} A^{\prime \prime}$ & 6.753 & 0.0015 & 6.692 & 0.0020 & 6.692 & 0.0020 \\
\hline \multirow[t]{2}{*}{$1^{1} A^{\prime}$} & 6.730 & 0.0019 & 6.729 & 0.0018 & 6.729 & 0.0018 \\
\hline & \multicolumn{2}{|c|}{ aug-cc-pV(T+d)Z } & \multicolumn{2}{|c|}{ d-aug-cc-pV(T+d)Z } & \multicolumn{2}{|c|}{ aug-cc-pVTZ+spd } \\
\hline & & & \multicolumn{2}{|c|}{$\mathrm{HClC}=\mathrm{C}=\mathrm{C}=\mathrm{O}$} & & \\
\hline $1{ }^{1} A^{\prime \prime}$ & 2.560 & 0.0002 & 2.559 & 0.0002 & 2.559 & 0.0002 \\
\hline $1^{1} A^{\prime}$ & 4.903 & 0.0813 & 4.902 & 0.0809 & 4.902 & 0.0812 \\
\hline $2{ }^{1} A^{\prime \prime}$ & 6.103 & 0.0000 & 6.103 & 0.0000 & 6.103 & 0.0000 \\
\hline \multirow[t]{2}{*}{$3{ }^{1} A^{\prime \prime}$} & 6.208 & 0.0023 & 6.205 & 0.0023 & 6.207 & 0.0023 \\
\hline & \multicolumn{6}{|c|}{$\mathrm{HClC}=\mathrm{C}=\mathrm{C}=\mathrm{C}=\mathrm{O}$} \\
\hline $1{ }^{1} A^{\prime \prime}$ & 1.731 & 0.0000 & 1.731 & 0.0000 & 1.731 & 0.0000 \\
\hline $1{ }^{1} A^{\prime}$ & 4.723 & 0.0431 & 4.722 & 0.0446 & 4.722 & 0.0431 \\
\hline $2{ }^{1} A^{\prime \prime}$ & 5.085 & 0.0001 & 5.085 & 0.0002 & 5.085 & 0.0001 \\
\hline $3{ }^{1} A^{\prime \prime}$ & 5.544 & 0.0016 & 5.516 & 0.0016 & 5.520 & 0.0016 \\
\hline
\end{tabular}

Furthermore, the method employed to compute the reference geometry is largely irrelevant. Vertical excitation energies computed at the EOM-CCSD level with different basis sets for the different optimized geometries are displayed in Figure 4 in the SI for each of the molecules in question. The corresponding energies are reported in Tables 15-27 in the SI. The comparison of the EOM-CCSD/d-aug-cc-pV(T+d)Z excited state energies computed for the three different optimized geometries for each molecule is shown. The discrepancies are largely insignificant being smaller than $0.1 \mathrm{eV}$ for $\mathrm{ClHCO}, \mathrm{ClHC}_{2} \mathrm{O}$, and $\mathrm{ClHC}_{4} \mathrm{O}$, and they are around $0.1 \mathrm{eV}$ for $\mathrm{ClHC}_{3} \mathrm{O}$. The $3{ }^{1} A^{\prime \prime}$ state in $\mathrm{ClHC}_{3} \mathrm{O}$ is an exception, which displays apparent differences between the three methods with 6.205, 6.465, $6.371 \mathrm{eV}$ for CCSD(T), B3LYP, and MP2, respectively. The largest difference among different methods is $0.260 \mathrm{eV}$ between B3LYP and $\operatorname{CCSD}(\mathrm{T})$ for $\mathrm{ClHC}_{3} \mathrm{O}$, but this is an outlier. Hence, the choice of method for computing the reference geometry does not have a notable effect on the excitation energy into the VUV.

The EOM-CCSD vertical excitation energy decreases with re- spect to the extension of the cumulenic chain for the transitions originating from the plane as shown in Figure 3 . The $\mathrm{A}^{\prime \prime}$ transitions in the cumulenone chloride series also adapt the same pattern with an exception of $\mathrm{ClHC}_{3} \mathrm{O}$. Excluding the lowest $\mathrm{A}^{\prime \prime}$ excitation, promotion of an electron out of the plane requires more energy for $\mathrm{ClHC}_{3} \mathrm{O}$ than $\mathrm{ClHC}_{2} \mathrm{O}$.

\subsubsection{Formyl Chloride}

Chloromethane $\left(\mathrm{CH}_{3} \mathrm{Cl}\right)$ and formaldehyde $\left(\mathrm{H}_{2} \mathrm{CO}\right)$ are well investigated in both experiment and theory. Investigations on the Rydberg series of these molecules provide that $\mathrm{CH}_{3} \mathrm{Cl}$ and $\mathrm{C}=\mathrm{O}$ functional groups have their Rydberg series start around 8.81 and $7.09 \mathrm{eV}$, respectively 8486 . By containing both of these groups, the Rydberg series of $\mathrm{ClCHO}$ is expected to occur in the vicinity of $8.0 \mathrm{eV}$. While the Ahldrichs's and correlation consistent sets are largely self-consistent, the discrepancies between corresponding transition energy between basis classes are significant with differences from $0.02 \mathrm{eV}$ to $1.61 \mathrm{eV}$ for higher-energy transitions. Since EOM-CCSD is a variational method and the correlation consistent basis provide much lower values for the energy levels, the correlation consistent energies are concluded to be more reliable. Hence, the correlation consistent basis sets are used to predict the properties of the rest of the $\mathrm{Cl}$-cumulenone series.

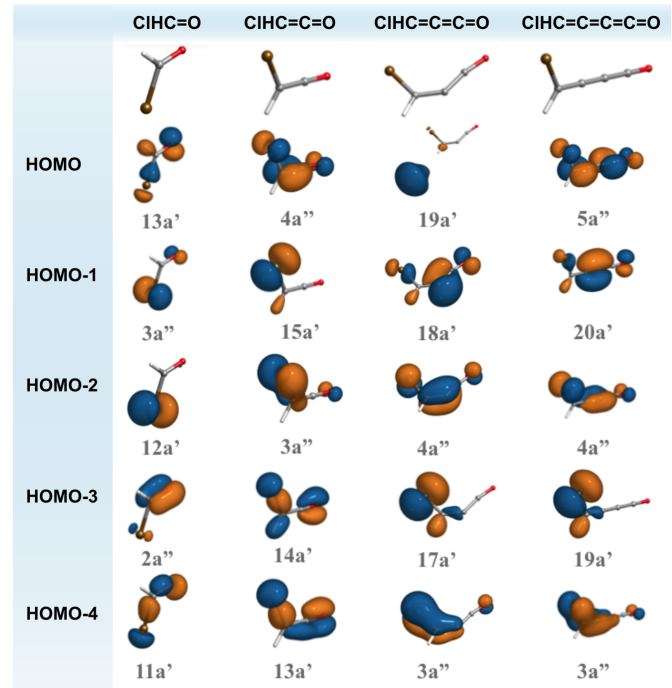

Fig. 4 Molecular orbitals of cumulenone chlorides: Highest occupied molecular orbitals ( $\mathrm{HOMO}$ ) of $\mathrm{ClHCO}, \mathrm{ClHC}_{2} \mathrm{O}, \mathrm{ClHC}_{3} \mathrm{O}, \mathrm{ClHC}_{4} \mathrm{O}$ computed at HF-SCF/t-aug-cc-pV $(\mathrm{T}+\mathrm{d}) \mathrm{Z}$ level of theory.

In $\mathrm{ClCHO}$, there is a non-negligible $(0.085 \mathrm{eV})$ decrease in the exictation energy computed with the aug-cc-pV(T+d)Z basis set as compared to that from d-aug-cc-pV(T+d)Z for the $4{ }^{1} A^{\prime}$ state and higher. The energies converge when more diffuse functions are added with the t-aug-cc-pV(T+d)Z basis as they match the doubly augmented basis to the significant digits reported here implying Rydberg-character in this state. This trend continues for the higher-energy states of $\mathrm{ClCHO}$. As a result, the following discussion will be based upon EOM-CCSD/t-aug-cc-pV(T+d)Z results.

Consistent with the order of ionizations, the highest occupied molecular orbitals (HOMO) is the oxygen lone pair, $n_{O}\left(13 \mathrm{a}^{\prime}\right)$; 
(HOMO-1) is an out-of-plane chlorine lone pair, $n_{C l}\left(3 \mathrm{a}^{\prime \prime}\right)$; and (HOMO-2) is an in-plane chlorine lone pair $n_{C l}\left(12 \mathrm{a}^{\prime}\right.$ ) (Figure 4). The first transition at $4.951 \mathrm{eV}$ is an $\pi_{\mathrm{CO}}^{*} \leftarrow n_{\mathrm{O}}$ transition, which is optically dark, where $\pi^{*}$ orbital is localized on the carbonyl with minor diffuse character on $\mathrm{Cl}$ (Figure 5 \& Table 3). EOMCCSD predicts the transition into the first excited state, $1^{1} A^{\prime \prime}$, to be $4.951 \mathrm{eV}$, which is $0.089 \mathrm{eV}$ lower than the result computed with MRD-CI+Q/cc-pVDZ+spd, $5.04 \mathrm{eV} 87$. The EOM-CCSD energy, however, is closer to the gas phase experimental measurement at $4.86 \mathrm{eV} 88$. The discrepancies between EOM-CCSD and $\mathrm{MRD}-\mathrm{CI}+\mathrm{Q} / \mathrm{cc}-\mathrm{pVDZ}+\mathrm{spd}$ vary from $0.083-0.916 \mathrm{eV}$, where the largest difference is for the $3^{1} A^{\prime \prime}$ state where, again, the present EOM-CCSD results are taken to be more reliable from the previous and current (above) benchmarks (Table 15 in the SI).

The next two lowest excited states, $1{ }^{1} A^{\prime}$ and $2{ }^{1} A^{\prime \prime}$, share the same electronic excitation character as $1^{1} A^{\prime \prime}$ (Figure 5), indicating that these three come as a set of excitations out of degenerate $p$ orbital groupings from the chlorine atom. However, $1^{1} A^{\prime}$ is marginally brighter than the other two with $f=0.0191$ due to the population of electrons being excited not only from the $n_{C l}$ $\left(\mathrm{a}^{\prime \prime}\right)$ but also from the $n_{C l}\left(\mathrm{a}^{\prime}\right)$. This increases the orbital overlap as well as the brightness of the transition. Meanwhile, the $1^{1} A^{\prime \prime}$ and $2{ }^{1} A^{\prime \prime}$ states have electrons excited out of $n_{\mathrm{O}}\left(\mathrm{a}^{\prime}\right)$ and $n_{\mathrm{Cl}}\left(\mathrm{a}^{\prime}\right)$ orbitals to out-of-plane orbitals. The poor overlap between the occupied and the virtual molecular orbitals renders these transitions optically dark.

The next set of transitions, $3{ }^{1} A^{\prime}, 4{ }^{1} A^{\prime}$, and $3{ }^{1} A^{\prime \prime}$, share the same $\sigma^{*}$ electronic character with diffuse characters located on $\mathrm{Cl}$ (Figure 5). The $4{ }^{1} A^{\prime}$ state is the only bright transition with $f$ $=0.3407$, owing to the same symmetry excitation from $n_{\mathrm{O}}\left(13 \mathrm{a}^{\prime}\right)$ to $\sigma_{C C l}^{*}$. These states are much closer in energy than the previous set where the order of the orbitals out of which the excitation occurs is reversed. Specifically, the lowest excitation originates from $n_{\mathrm{Cl}}\left(3 \mathrm{a}^{\prime \prime}\right)$, and the highest transition involves $n_{\mathrm{Cl}}\left(13 \mathrm{a}^{\prime}\right)$.

The Rydberg series of ClCHO starts at $8.143 \mathrm{eV}$ close to the 8.0 $\mathrm{eV}$ point hypothesized above from averaging the Rydberg excitations of $\mathrm{Cl}$-bearing and $\mathrm{C}=\mathrm{O}$-containing species. This series is also the third trio of states and consists of the $2{ }^{1} A^{\prime}, 4{ }^{1} A^{\prime \prime}$, and $5^{1} A^{\prime}$ states. The $2{ }^{1} A^{\prime}$ and $4{ }^{1} A^{\prime \prime}$ states lies $1 \mathrm{eV}$ apart, where diffuse orbitals are localized around the HCCl bond angle from Figure 5. The $4{ }^{1} A^{\prime \prime}$ and $5^{1} A^{\prime}$ states are nearly degenerate at 9.099 and $9.097 \mathrm{eV}$ with comparable oscillator strengths of 0.0532 and 0.0485 , respectively. Both of these states are relatively dim as compared to the $4{ }^{1} A^{\prime}$. The $2{ }^{1} A^{\prime}$ state is marginally brighter due to the same symmetry excitation and better orbital overlap of the occupied and virtual orbitals. Although they appear to be different, $5^{1} A^{\prime}$ and $4{ }^{1} A^{\prime \prime}$ are topologically similar as they share similar valence character again shown in Figure 5. Thus the, $5{ }^{1} A^{\prime}$ fits in well with this set owing to its electronic character. It is, however, much more diffuse with an $s$-Rydberg present in the transition. The diffuseness leads to a small discrepancy in the energies of the two states since diffuse electron density tends to lower the energy of the state 6 .

Since there is some valence character present in addition to diffuse characters, this trio of states as well as the $5^{1} A^{\prime \prime}$ state provide for the lowest energy valence-Rydberg mixing transitions as exhibited in Figure 5. States $5{ }^{1} A^{\prime}$ and $5{ }^{1} A^{\prime \prime}$ have the most prominent diffuse character of orbitals, where the $5{ }^{1} A^{\prime}$ state exhibits $s$-Rydberg mixing at $9.097 \mathrm{eV}$ and the $5{ }^{1} A^{\prime \prime}$ state shows $p$-Rydberg character. The Rydberg series in ClCHO is approximately $1.0 \mathrm{eV}$ higher than formaldehyde, which occurs at 7.08 $\mathrm{eV} 86$.

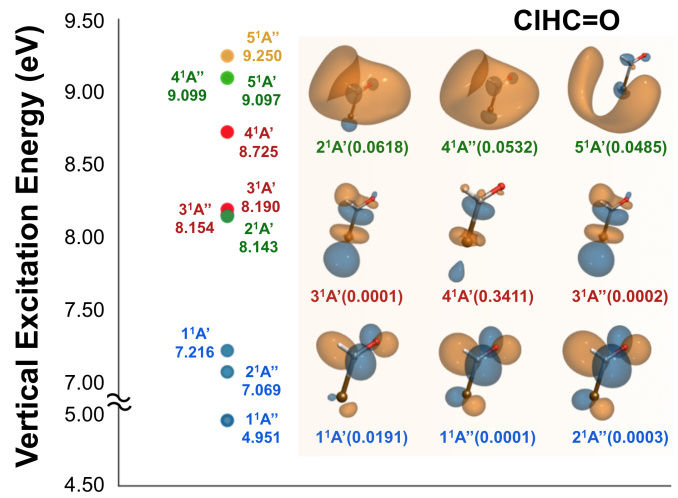

Fig. 5 Excited state properties of formyl chloride: The vertical excitation energies with the corresponding symmetry computed at EOM-CCSD/t-augcc-pV $(T+d) Z$ are shown on the left. The color code-blue, red, greendistinguishes different sets of transitions. The excited state transition orbitals of each set are displayed on the right panel with the corresponding color code. The molecular orbital isosurfaces are $0.03,0.02,0.01 \mathrm{e}^{2} /$ Bohr for the bottom, middle, and top group of transitions.

\subsubsection{Chloroketene}

The aug-cc-pV(T+d)Z energies are consistently $0.1 \mathrm{eV}$ larger than the energies computed with the d-aug-cc-pV(T+d)Z basis up to $6{ }^{1} A^{\prime \prime}$ (Table 3). More details can be found in Table 19 in the SI. The energy gap between the two bases rises to $0.5-0.6 \mathrm{eV}$ starting at $7{ }^{1} A^{\prime \prime}(\sim 7.9 \mathrm{eV})$ due to the significant increase in the diffuseness of the electrons, an indication of Rydberg character. This pattern is only predicted for states that are higher than 8 $\mathrm{eV}$ even though the Rydberg series starts at $5.749 \mathrm{eV}$ for $2{ }^{1} A^{\prime \prime}$. This pattern is not quite as pronounced in the case of $\mathrm{ClCHO}$ where the largest shift is approximately $0.2-0.3 \mathrm{eV}$. However, and like $\mathrm{ClCHO}$, the t-aug-cc-pV(T+d)Z basis set is used for discussion here since the properties are considered converged for such diffuseness.

The first transition of $\mathrm{ClHC}_{2} \mathrm{O}$ at $3.057 \mathrm{eV}$ is $1.894 \mathrm{eV}$ lower than that of ClCHO. $1^{1} A^{\prime}, 1{ }^{1} A^{\prime \prime}$, and $6{ }^{1} A^{\prime \prime}$ form a trio of states that, again, possess the same qualitative topology with electrons being excited out of the $\pi\left(4 \mathrm{a}^{\prime \prime}\right), n_{C l}\left(15 \mathrm{a}^{\prime}\right)$, and $n_{C l, O}\left(3 \mathrm{a}^{\prime \prime}\right)$ orbitals (Figure 4). While $1^{1} A^{\prime \prime}$ is completely dark, $1^{1} A^{\prime}$ has a marginally larger oscillator strength than the $6{ }^{1} A^{\prime \prime}$ state due to better overlap from occupied and virtual orbitals of the same symmetry. The energy of the $6{ }^{1} A^{\prime \prime}$ is lowered by $2.3 \mathrm{eV}$ in $\mathrm{ClHC}_{2} \mathrm{O}$ as compared to the corresponding transition in $\mathrm{ClCHO}$, allowing it to form a set with $1^{1} A^{\prime}$ and $1{ }^{1} A^{\prime \prime}$ instead of $2{ }^{1} A^{\prime \prime}$ in the case of ClCHO. While the $2{ }^{1} A^{\prime \prime}$ excitation only originates from $\pi\left(4 \mathrm{a}^{\prime \prime}\right)$, the transition into the $6{ }^{1} A^{\prime \prime}$ state involves participation from both the $\pi\left(4 \mathrm{a}^{\prime \prime}\right)$ and $n_{C l, O}\left(3 \mathrm{a}^{\prime \prime}\right)$ orbitals (Figure 6).

Besides $3{ }^{1} A^{\prime}$, the rest of the chloroketene excited state transitions are diffuse Rydberg mixing with valence character. The 
A

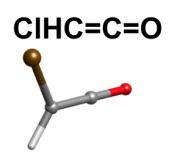

B

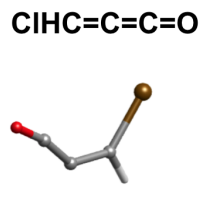

C

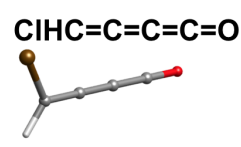

D

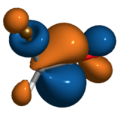

1'A" 3.057(0.0000)

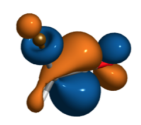

$1^{1} A^{\prime}$ 6.739(0.0018)

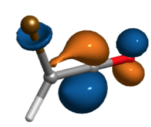

$6^{1} A " 7.729(0.0002)$
G

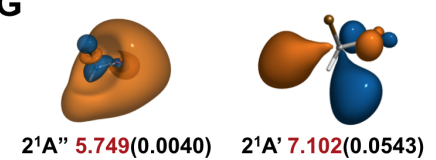

E

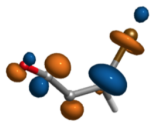

$3^{1}$ A" 6.205(0.0023)
$3^{1} A^{\prime} \quad 6.965(0.4237) \quad 7^{1} A^{\prime} 7.876(0.1548)$

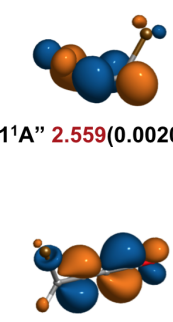

11A" 1.731(0.0000)
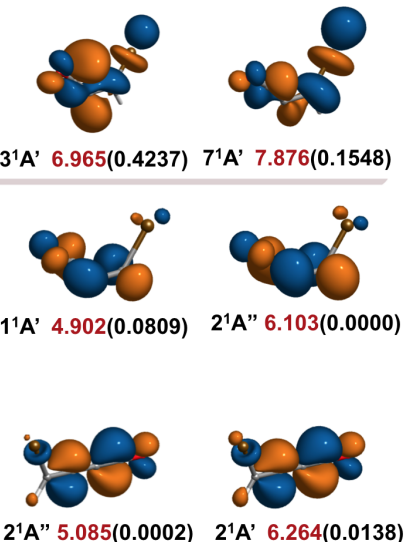

H

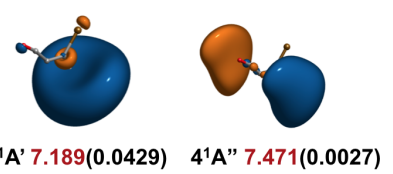

4$^{1} \mathrm{~A}^{\prime} 7.189(0.0429) \quad 4^{1} \mathrm{~A}^{\prime \prime} 7.471(0.0027)$

I

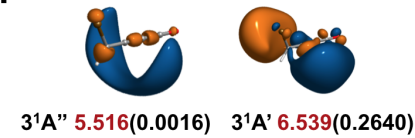

Fig. 6 Excited state transition orbitals: Ground state geometries of (A) chloroketene, (B) propadieneone chloride, (C) butatrienone chloride. The group(s) of orbitals with the same character for each molecule computed at CCSD(T)/t-aug-cc-pV(T+d)Z are shown in panels (D), (E), (F), respectively. The lowest Rydberg-valence transitions of two symmetries for each molecule are shown in panels $(G),(H),(I)$. The state assignment, associated vertical excitation energy in red, and oscillator strength in parentheses of each transition are specified underneath. The isosurfaces (iso) used for plotting the excited state molecular orbitals for $\mathrm{ClHC}_{2} \mathrm{O}$ are (D) 0.035 and (G) 0.005 (left) and 0.011 (right) $\mathrm{e}^{2} / \mathrm{Bohr}$, for $\mathrm{ClHC} \mathrm{C}_{3} \mathrm{O}$ are (E) $0.025,0.0125,(\mathrm{H}) 0.040 \mathrm{e}^{2} /$ Bohr, and for $\mathrm{ClHC}_{4} \mathrm{O}$ are (F) 0.035 and (I) $0.0125 \mathrm{e}^{2} /$ Bohr.

Rydberg series starts with the $2{ }^{1} A^{\prime \prime}$ transition with electrons being excited out of the $\pi\left(4 \mathrm{a}^{\prime \prime}\right)$ cloud, resulting in valence orbitals mixing with an $s$-Rydberg localized on the $\mathrm{C}=\mathrm{O}$ bond (Figure $6 G$ ). Meanwhile, $2{ }^{1} A^{\prime}$ at $7.102 \mathrm{eV}$ is the lowest Rydberg-valence state-with a $p$-Rydberg localized on $C_{\beta}$-for the in-plane transitions. Rydberg character in chloroketene starts at $2 \mathrm{eV}$ lower than in formyl chloride, which appears at around 8 and $9 \mathrm{eV}$ for the $\mathrm{A}^{\prime}$ and $\mathrm{A}^{\prime \prime}$ series, respectively (Figure 6G). The dramatic increase in the diffuse character in $\mathrm{ClHC}_{2} \mathrm{O}$ is exhibited through the dropping of vertical excitation energies with more diffuse basis sets and the orbital characters. Overall, the computed properties of the lowest 15 excited states yield no evidence of the Rydberg series converging to the excited states of the the cation.

\subsubsection{Propadienone Chloride}

Propadienone is known for its peculiar structure where an inplane nonlinearity is observed in the allylic carbon chain 73 . The addition of two carbons along with chlorine substitution raises the cost of the calculations relative to the benchmarks from formyl chloride. Therefore, the TZ+spd basis sets are employed here where computational cost is reduced with little-to-no sacrifice in accuracy 6870 . This basis set is benchmarked for ClHCO in the SI. There are no dramatic differences in the $\mathrm{TZ}+$ spd basis compared with t-aug-cc-pV(T+d)Z. Furthermore, shifts from the augcc-pVTZ excited state energy compared with either $\mathrm{TZ}+s p d$ or t-aug-cc-pV $(\mathrm{T}+\mathrm{d}) \mathrm{Z}$ are consistent. Hence, this basis is utilized for the most diffuse computations in $\mathrm{ClHC}_{3} \mathrm{O}$.

Figures 5 and 6 s show that lowest two groups of excitations in $\mathrm{ClHCO}$ and $\mathrm{ClHC}_{3} \mathrm{O}$ share similar electronic characters. Specifically, the $1^{1} A^{\prime \prime}, 1^{1} A^{\prime}$, and $2^{1} A^{\prime \prime}$ states form a set in both ClHCO and $\mathrm{ClHC}_{3} \mathrm{O}$ where $1^{1} A^{\prime}$ is the brightest due to a better orbital overlap of the same symmetry excitation. The $\pi$-cloud localized along the carbon chain is also extended to the oxygen atom with minor diffuse character on the chlorine atom. This same behavior is present in chloroketene where the $\pi$ cloud is extended. The electron densities in these excitations originate from HOMO = $n_{O}\left(18 \mathrm{a}^{\prime}\right)$, (HOMO-1) $=n_{C l}\left(4 \mathrm{a}^{\prime \prime}\right)$, and (HOMO-2) $=n_{C l}\left(17 \mathrm{a}^{\prime}\right)$ (Figure 4). The $1^{1} A^{\prime}$ state results from a mixed transition with electron densities being excited from mostly $n_{C l}\left(4 \mathrm{a}^{\prime \prime}\right)$ with a minor contribution from $n_{O}\left(18 \mathrm{a}^{\prime}\right)$. The greater orbital overlaps render it a dim transition as compared to the other two. Moreover, the electronic character of state $8^{1} A^{\prime}$ also seems to resemble this group with an addition of some $s$-Rydberg (Figure $2 \&$ Table 22 in SI).

The second trio of near-degenerate states consists of the $3{ }^{1} A^{\prime}, 3{ }^{1} A^{\prime \prime}$, and $7^{1} A^{\prime}$, where $3{ }^{1} A^{\prime \prime}$ is the darkest state due to the poor orbital overlap resulting from out-of-plane excitations. A non-bonding orbital along the $\mathrm{CCl}$ bond is seen for both $\mathrm{ClHCO}$ and $\mathrm{ClHC}_{3} \mathrm{O}$. Moreover, state $3{ }^{1} A^{\prime}$ is also the brightest among all the excitations reported for this molecule with $f=0.4237$. This excitation is contaminated by some population from the (HOMO1) in addition to the HOMO. Meanwhile, $7{ }^{1} A^{\prime}$ involves a minor contribution from the (HOMO-3) in addition to the (HOMO-2) and is also a bright transition.

The lowest Rydberg-valence transitions in both symmetries appear for the $4{ }^{1} A^{\prime}(7.189 \mathrm{eV})$ and $4{ }^{1} A^{\prime \prime}(7.471 \mathrm{eV})$ states (Figure $6 \mathrm{H})$. In both cases, the $s$-Rydberg and $p$-Rydberg are dominant, respectively. The energy gap of these two Rydberg states is $0.282 \mathrm{eV}$, which is slightly larger than the energy difference of the lowest Rydberg states of the two symmetries in $\mathrm{ClCHO}, 0.011 \mathrm{eV}$. 
Both of these differences are much smaller than that of $\mathrm{ClHC}_{2} \mathrm{O}$, which is $1.302 \mathrm{eV}$.

\subsubsection{Butatrienone Chloride}

Even though butatrienone interchanges between the linear and out-of-plane Cs configurations, such relatively small differences in the structure of the molecule do not change its orbital topology by any meaningful amount. Hence, the actual structure of the backbone will be insignificant for computing meaningful properties, such as electronic excitation energies, ionization energies, and oscillator strengths. In point, the excited state energies computed at the EOM-CCSD for three optimized geometries, even with some bent and other linear, are in excellent agreement as shown in Figure 8 in the SI. Consequently, the linear configuration will be used for all vertical excitation energy computations.

There is a similarity between the first set of excitations in the even $n$ species (Figure 6P \& E). The excitation characters of the first set in $\mathrm{ClHC}_{4} \mathrm{O}$ closely resemble those of $\mathrm{ClHC}_{2} \mathrm{O}$ where $1^{1} A^{\prime}$ and $6{ }^{1} A^{\prime \prime}$ are replaced by $2{ }^{1} A^{\prime}$ and $2{ }^{1} A^{\prime \prime}$, respectively. The elongation of the conjugated system stabilizes the entire molecule and, thus, significantly lowers the energy for the last component of this set.

The lowest Rydberg-valence transitions in both symmetries are found for the $3{ }^{1} A^{\prime}(6.539 \mathrm{eV})$ and $3{ }^{1} A^{\prime \prime}(5.516 \mathrm{eV})$ states (Figure 6,). The $3{ }^{1} A^{\prime \prime}$ state is dominated with $s$-Rydberg character while the $3{ }^{1} A^{\prime}$ state is surrounded by a $p$-Rydberg orbital with $\pi$ valence character. The energy gap between the two lowest Rydberg-valence transitions is $1.023 \mathrm{eV}$, which is $0.3 \mathrm{eV}$ lower than that of $\mathrm{ClHC}_{2} \mathrm{O}$. The transition into the $3{ }^{1} A^{\prime}$ state has a significantly brighter oscillator strength, 0.2640 , due to a much greater orbital overlap. The Rydberg-valence states of the two symmetries of the even $n$ species seem to have a bigger energy difference (more than $1.0 \mathrm{eV}$ ) as compared to the odd $n$ molecules which is less than $0.3 \mathrm{eV}$. The extension of the carbon chain not only decreases the energy levels for most states but also lowers the Rydberg series. Similar to $\mathrm{ClHC}_{2} \mathrm{O}$, there is approximately a $0.5 \mathrm{eV}$ difference in energy starting with the transition into the $5^{1} A^{\prime}$ state, where significant diffuse character starts to appear (Figure 3 and Table 25 in the SI).

\section{Conclusions}

The behavior of the cumulenone chlorides is in many ways an average of the effects observed in regular cumulenone molecules and organochlorides. The structures of formyl chloride and chloroketene strongly resemble the corresponding hydrocarbon species, indicating that the chlorine atom has a minor contribution towards the chemical interactions that determine the bonding structure of the system. Meanwhile, the chlorine replacement perturbs the structures of $\mathrm{ClHC}_{3} \mathrm{O}$ and $\mathrm{ClHC}_{4} \mathrm{O}$ and leads to slight differences to a much greater extent as compared to the corresponding cumulenone species. The substitution effect is displayed via the discrepancies in the ionization energies for the chlorinated series as they are approximately $1 \mathrm{eV}$ higher than the cumulenones. This is likely caused by the cation-formed postionization-becoming less stable due to the presence of the chlorine atom. The carbene character is enhanced in $\mathrm{ClHC}_{3} \mathrm{O}$ as com- pared to $\mathrm{H}_{2} \mathrm{CHO}$ as more bending is observed on the beta carbon. Differently, $\mathrm{ClHC}_{4} \mathrm{O}$, with a soft backbone, undergoes low-energy large amplitude motion and interchanges between out-of-plane bending and linearity. Even so, the geometries and ionization energies computed here for formyl chloride and chloroketene are in excellent agreement with microwave spectroscopic measurements indicating that such computed properties are likely valid for these as-of-yet unobserved species.

Similar to the ionization energies, the Rydberg series of the chlorinated systems also starts about $1 \mathrm{eV}$ higher than the cumulenone family. Electronic excitations from the two chlorine lone-pairs and an oxygen lone-pair form different groups of excitations that consist of three different states sharing the same character originating from the valence $p$ orbitals on the chlorine atom. These transitions may ultimately lead to a chain of reactions that are directly relevant to atmospheric science and astrochemistry. Halochemistry of the former is well-established, but that of the latter is just emerging. The kinetics for the photolysis and the successive collisions between the resulting radicals and other species can be further investigated experimentally as has been done recently 16 . Hence, the obtained photophysical properties of these systems will potentially enable the modeling of such reactions that occur in both the stratosphere and the ISM.

\section{Conflicts of interest}

The authors have no conflicts to declare.

\section{Acknowledgements}

Q.L.N and W.K.P acknowledges support from Department of Energy Office of Basic Energy Sciences (DE-SC0012628). Q.L.N. was also supported by the National Science Foundation Graduate Research Fellowship (DGE-1144083). R.C.F. acknowledges support from the National Aeronautics and Space Administration (NNX17AH15G) and from the National Science Foundation (OIA1757220). We thank Michael Tanksavala for helpful discussions and Prof. Margaret M. Murnane and Prof. G. Barney Ellison for the support of this work and comments on the manuscript.

\section{Notes and references}

1 J. Berkowitz, Photoabsorption, Photoionization, and Photoelectron Spectroscopy, Academic Press, Newyork, 1979.

2 R. W. Shaw, T. B. Brill and D. L. Thompson, Overviews of recent research on energetic materials, World Scientific, Singapore, 2005.

3 D. D. Dlott, Energetic Materials, Elsevier, 2003, vol. 13, pp. $125-191$.

4 M. Kuklja, Applied Physics A, 2003, 76, 359-366.

5 D. R. Marsh, in Chemical-Dynamical Coupling in the Mesosphere and Lower Thermosphere, ed. M. A. Abdu and D. Pancheva, Springer Netherlands, Dordrecht, 2011, pp. 317.

6 H. Lühr, H. Liu, J. Park and S. Müller, in New Aspects of the Coupling Between Thermosphere and Ionosphere, with Special regards to CHAMP Mission Results, ed. M. A. Abdu and 
D. Pancheva, Springer Netherlands, Dordrecht, 2011, pp. 303-316.

7 C. He, S. M. Hörst, N. K. Lewis, J. I. Moses, E. M.-R. Kempton, M. S. Marley, C. V. Morley, J. A. Valenti and V. Vuitton, ACS Earth and Space Chemistry, 2019, 3, 39-50.

8 K. I. Öberg, Chemical Reviews, 2016, 116, 9631-9663.

9 D. K. Böhme, Phys. Chem. Chem. Phys., 2011, 13, 1825318263.

10 H. Reisler and A. I. Krylov, International Reviews in Physical Chemistry, 2009, 28, 267-308.

11 M. B. Robin, Higher Excited States of Polyatomic Molecules, Academic Press, 1970.

12 T. Mori, W. J. Glover, M. S. Schuurman and T. J. Martinez, The Journal of Physical Chemistry A, 2012, 116, 2808-2818.

13 E. G. Champenois, N. H. Shivaram, T. W. Wright, C.-S. Yang, A. Belkacem and J. P. Cryan, The Journal of Chemical Physics, 2016, 144, 014303.

14 T. Geng, O. Schalk, S. P. Neville, T. Hansson and R. D. Thomas, The Journal of Chemical Physics, 2017, 146, 144307.

15 S. P. Neville and G. A. Worth, The Journal of Chemical Physics, 2014, 140, 034317.

16 W. K. Peters, D. E. Couch, B. Mignolet, X. Shi, Q. L. Nguyen, R. C. Fortenberry, H. B. Schlegel, F. Remacle, H. C. Kapteyn, M. M. Murnane and W. Li, Proceedings of the National Academy of Sciences, 2017, E11072-E11081.

17 D. W. Turner, Molecular Photoelectron Spectroscopy: A Handbook of He $584 \AA$ A Spectra, Wiley Interscience, London, 1970.

18 B. R. Lewis, A. N. Heays, S. T. Gibson, H. Lefebvre-Brion and R. Lefebvre, The Journal of Chemical Physics, 2008, 129, 164306.

19 H. Lefebvre-Brion and M. Eidelsberg, Journal of Molecular Spectroscopy, 2012, 271, 59 - 65.

20 M. O. Vieitez, T. I. Ivanov, C. A. de Lange, W. Ubachs, A. N. Heays, B. R. Lewis and G. Stark, The Journal of Chemical Physics, 2008, 128, 134313.

21 G. Schönnenbeck, H. Biehl, F. Stuhl, U. Meier and V. Staemmler, The Journal of Chemical Physics, 1998, 109, 2210-2219.

22 D. Frost, C. McDowell and N. Westwood, Chemical Physics Letters, 1977, 51, $607-610$.

23 Q. S. Li and Q. Luo, The Journal of Physical Chemistry A, 2003, 107, 10435-10440.

24 G. Fantechi, N. R. Jensen, O. Saastad, J. Hjorth and J. Peeters, Journal of Atmospheric Chemistry, 1998, 31, 247-267.

25 V. Catoire, R. Lesclaux, W. F. Schneider and T. J. Wallington, The Journal of Physical Chemistry, 1996, 100, 14356-14371.

26 T. J. Wallington, M. D. Hurley and W. F. Schneider, Chemical Physics Letters, 1996, 251, 164 - 173.

27 B. W. Gay, P. L. Hanst, J. J. Bufalini and R. C. Noonan, Environmental Science \& Technology, 1976, 10, 58-67.

28 J. P. Grotzinger, J. Crisp, A. R. Vasavada, R. C. Anderson, C. J. Baker, R. Barry, D. F. Blake, K. S. Conrad, Pamela aand Edgett, B. Ferdowski, R. Gellert, J. B. Gilbert, M. Golombek, J. Gómez-Elvira, D. M. Hassler, L. Jandura, M. Litvak, P. Mahaffy, J. Maki, M. Meyer, M. C. Malin, I. Mitrofanov, J. J. Sim- monds, D. Vaniman, R. V. Welch and R. C. Wiens, Space Science Reviews, 2012, 170, 1572-9672.

29 K. Biemann, J. Oro, P. Toulmin, L. E. Orgel, A. O. Nier, D. M. Anderson, P. G. Simmonds, D. Flory, A. V. Diaz, D. R. Rushneck and J. A. Biller, Science, 1976, 194, 72-76.

30 Lis, D. C., Pearson, J. C., Neufeld, D. A., Schilke, P., Müller, H. S. P., Gupta, H., Bell, T. A., Comito, C., Phillips, T. G., Bergin, E. A., Ceccarelli, C., Goldsmith, P. F., Blake, G. A., Bacmann, A., Baudry, A., Benedettini, M., Benz, A., Black, J., Boogert, A., Bottinelli, S., Cabrit, S., Caselli, P., Castets, A., Caux, E., Cernicharo, J., Codella, C., Coutens, A., Crimier, N., Crockett, N. R., Daniel, F., Demyk, K., Dominic, C., Dubernet, M.-L., Emprechtinger, M., Encrenaz, P., Falgarone, E., Fuente, A., Gerin, M., Giesen, T. F., Goicoechea, J. R., Helmich, F., Hennebelle, P., Henning, Th., Herbst, E., Hily-Blant, P., Hjalmarson, Ã., Hollenbach, D., Jack, T., Joblin, C., Johnstone, D., Kahane, C., Kama, M., Kaufman, M., Klotz, A., Langer, W. D., Larsson, B., Le Bourlot, J., Lefloch, B., Le Petit, F., Li, D., Liseau, R., Lord, S. D., Lorenzani, A., Maret, S., Martin, P. G., Melnick, G. J., Menten, K. M., Morris, P., Murphy, J. A., Nagy, Z., Nisini, B., Ossenkopf, V., Pacheco, S., Pagani, L., Parise, B., Pérault, M., Plume, R., Qin, S.-L., Roueff, E., Salez, M., Sandqvist, A., Saraceno, P., Schlemmer, S., Schuster, K., Snell, R., Stutzki, J., Tielens, A., Trappe, N., van der Tak, F. F. S., van der Wiel, M. H. D., van Dishoeck, E., Vastel, C., Viti, S., Wakelam, V., Walters, A., Wang, S., Wyrowski, F., Yorke, H. W., Yu, S., Zmuidzinas, J., Delorme, Y., Desbat, J.-P., Güsten, R., Krieg, J.-M. and Delforge, B., Astronomy \& Astrophysics, 2010, 521, L9.

31 D. A. Neufeld, E. Roueff, R. L. Snell, D. Lis, A. O. Benz, S. Bruderer, J. H. Black, M. D. Luca, M. Gerin, P. F. Goldsmith, H. Gupta, N. Indriolo, J. L. Bourlot, F. L. Petit, B. Larsson, G. J. Melnick, K. M. Menten, R. Monje, Z. Nagy, T. G. Phillips, A. Sandqvist, P. Sonnentrucker, F. van der Tak and M. G. Wolfire, The Astrophysical Journal, 2012, 748, 37.

32 M. D. Luca, H. Gupta, D. Neufeld, M. Gerin, D. Teyssier, B. J. Drouin, J. C. Pearson, D. C. Lis, R. Monje, T. G. Phillips, J. R. Goicoechea, B. Godard, E. Falgarone, A. Coutens and T. A. Bell, The Astrophysical Journal Letters, 2012, 751, L37.

33 W.-H. Fang and R.-Z. Liu, The Journal of Chemical Physics, 2001, 115, 10431-10437.

34 W. M. Irvine, L. W. Avery, P. Friberg, H. E. Matthews and L. M. Ziurys, Astrophysical letters and communications, 1988, 26, $167 \mathrm{a} 180$.

35 M. Guelin, N. N. and J. Cernicharo, Astronomy and Astrophysics, 1998, 335, L1-L4.

36 J. Cernicharo, A. M. Heras, A. G. G. M. Tielens, J. R. Pardo, F. Herpin, M. Guélin and L. B. F. M. Waters, The Astrophysical Journal, 2001, 546, L123-L126.

37 L. M. Ziurys, Proceedings of the National Academy of Sciences, 2006, 103, 12274-12279.

38 A. Inness, F. Baier, A. Benedetti, I. Bouarar, S. Chabrillat, H. Clark, C. Clerbaux, P. Coheur, R. J. Engelen, Q. Errera, J. Flemming, M. George, C. Granier, J. Hadji-Lazaro, V. Huijnen, D. Hurtmans, L. Jones, J. W. Kaiser, J. Kapsomenakis, 
K. Lefever, J. Leitão, M. Razinger, A. Richter, M. G. Schultz, A. J. Simmons, M. Suttie, O. Stein, J.-N. Thépaut, V. Thouret, M. Vrekoussis, C. Zerefos and the MACC team, Atmospheric Chemistry and Physics, 2013, 13, 4073-4109.

39 N. Washida, S. Hatakeyama, H. Takagi, T. Kyogoku and S. Sato, The Journal of Chemical Physics, 1983, 78, 45334540 .

40 L. E. Snyder, D. Buhl, B. Zuckerman and P. Palmer, Physical Review Letters, 1969, 22, 679-681.

41 W. M. Irvine, R. D. Brown, D. M. Cragg, P. Friberg, P. D. Godfrey, N. Kaifu, H. E. Matthews, M. Ohishi, H. Suzuki and H. Takeo, The Astrophysical Journal Letters, 1988, 335, L89.

42 H. E. Matthews, W. M. Irvine, P. Friberg, R. D. Brown and P. D. Godfrey, Nature, 1984, 310, 125-126.

43 K. B. Krauskopf and G. K. Rollefson, Journal of the American Chemical Society, 1934, 56, 2542-2548.

44 A. L. Cooksy, J. K. G. Watson, C. A. Gottlieb and P. Thaddeus, The Journal of Chemical Physics, 1994, 101, 178-186.

45 R. S. Timonen, E. Ratajczak and D. Gutman, The Journal of Physical Chemistry, 1988, 92, 651-655.

46 H. Niki, P. Maker, L. Breitenbach and C. Savage, Chemical Physics Letters, 1978, 57, 596 - 599.

47 M. C. L. Gerry, W. Lewis-Bevan and N. P. C. Westwood, The Journal of Chemical Physics, 1983, 79, 4655-4663.

48 H. Takeo and C. Matsumura, The Journal of Chemical Physics, 1976, 64, 4536-4540.

49 E. C. Fayolle, K. I. Öberg, J. K. Jørgensen, K. Altwegg, H. Calcutt, H. S. P. Müller, M. Rubin, M. H. D. van der Wiel, P. Bjerkeli, T. L. Bourke, A. Coutens, E. F. van Dishoeck, M. N. Drozdovskaya, R. T. Garrod, N. F. W. Ligterink, M. V. Persson and S. F. Wampfler, Nature Astronomy, 2017, 1, 703-708.

50 M. H. Hecht, S. P. Kounaves, R. C. Quinn, S. J. West, S. M. M. Young, D. W. Ming, D. C. Catling, B. C. Clark, W. V. Boynton, J. Hoffman, L. P. DeFlores, K. Gospodinova, J. Kapit and P. H. Smith, Science, 2009, 325, 64-67.

51 J. F. Stanton, J. Gauss, M. E. Harding, , P. G. Szalay, with Contributions from A. A. Auer, R. J. Bartlett, U. Benedikt, C. Berger, D. E. Bernholdt, Y. J. Bomble, L. Cheng, O. Christiansen, M. Heckert, O. Heun, C. Huber, T. Jagau, D. Jonsson, J. Juselius, K. Klein, W. J. Lauderdale, D. A. Matthews, T. Metzroth, L. A. Muck, D. P. ONeill, D. R. Price, E. Prochnow, C. Puzzarini, K. Ruud, F. Schiffmann, W. Schwalbach, C. Simmons, S. Stopkowicz, A. Tajti, J. Vazquez, F. Wang, J. D. Watts, the Integral Packages MOLECULE (J. Almlof, P. R. Taylor), P. P. R. Taylor), A. T. Helgaker, H. J. A. Jensen, P. Jorgensen, J. Olsen), E. R. by A. V. Mitin and C. van Wüllen, CFOUR, a Quantum Chemical Program Package. For the current version, see http://www.cfour.de.

52 J. M. Turney, A. C. Simmonett, R. M. Parrish, E. G. Hohenstein, F. A. Evangelista, J. T. Fermann, B. J. Mintz, L. A. Burns, J. J. Wilke, M. L. Abrams, N. J. Russ, M. L. Leininger, C. L. Janssen, E. T. Seidl, W. D. Allen, H. F. Schaefer, R. A. King, E. F. Valeev, C. D. Sherrill and T. D. Crawford, Wiley Interdisciplinary Reviews: Computational Molecular Science, 2012, 2, 556-565.

53 T. H. Dunning, The Journal of Chemical Physics, 1989, 90,
1007-1023.

54 A. D. Becke, The Journal of Chemical Physics, 1993, 98, 56485652.

55 P. J. Stephens, F. J. Devlin, C. F. Chabalowski and M. J. Frisch, The Journal of Physical Chemistry, 1994, 98, 11623-11627.

56 C. Møller and M. S. Plesset, Phys. Rev., 1934, 46, 618-622.

57 K. Raghavachari, G. W. Trucks, J. A. Pople and M. HeadGordon, Chemical Physics Letters, 1989, 157, 479 - 483.

58 T. H. D. Jr., K. A. Peterson and A. K. Wilson, The Journal of Chemical Physics, 2001, 114, 9244-9253.

59 J. F. Stanton and J. Gauss, The Journal of Chemical Physics, 1994, 101, 8938-8944.

60 M. Nooijen and R. J. Bartlett, The Journal of Chemical Physics, 1995, 102, 3629-3647.

61 D. Sinha, S. K. Mukhopadhay, M. Prasad and D. Mukherjee, Chemical Physics Letters, 1986, 125, 213 - 217.

62 J. F. Stanton and R. J. Bartlett, The Journal of Chemical Physics, 1993, 98, 7029-7039.

63 A. I. Krylov, Annual Review of Physical Chemistry, 2008, 59, 433-462.

64 F. Weigend, Phys. Chem. Chem. Phys., 2006, 8, 1057-1065.

65 F. Weigend and R. Ahlrichs, Phys. Chem. Chem. Phys., 2005, 7, 3297-3305.

66 R. C. Fortenberry and T. D. Crawford, The Journal of Chemical Physics, 2011, 134, 154304.

67 R. C. Fortenberry and T. D. Crawford, The Journal of Physical Chemistry A, 2011, 115, 8119-8124.

68 W. J. Morgan and R. C. Fortenberry, Theoretical Chemistry Accounts, 2015, 134, 47.

69 W. J. Morgan and R. C. Fortenberry, The Journal of Physical Chemistry A, 2015, 119, 7013-7025.

70 M. K. Bassett and R. C. Fortenberry, The Journal of Chemical Physics, 2017, 146, 224303.

71 T. J. Santaloci and R. C. Fortenberry, Molecular Astrophysics, 2020, 19, 100070.

72 W. Humphrey, A. Dalke and K. Schulten, Journal of Molecular Graphics, 1996, 14, 33 - 38.

73 R. D. Brown, P. D. Godfrey, R. Champion and D. McNaughton, Journal of the American Chemical Society, 1981, 103, 57115715.

74 R. A. Loomis, B. A. McGuire, C. Shingledecker, C. H. Johnson, S. Blair, A. Robertson and A. J. Remijan, The Astrophysical Journal, 2015, 799, 34.

75 R. D. Brown, R. F. C. Brown, F. W. Eastwood, P. D. Godfrey and D. McNaughton, Journal of the American Chemical Society, 1979, 101, 4705-4708.

76 A. Scott and L. Radom, Journal of Molecular Structure, 2000, 556, $253-261$.

77 R. D. Brown and R. G. Dittman, Chemical Physics, 1984, 83, $77-82$.

78 L. Farnell and L. Radom, Chemical Physics Letters, 1982, 91, $373-377$.

79 S. R. Langhoff and D. P. Chong, Chemical Physics Letters, 1983, 
$100,259-262$.

80 R. D. Brown, in Structural Information on Large Amplitude Motions, ed. J. Laane, M. Dakkouri, B. van der Veken and H. Oberhammer, Springer Netherlands, Dordrecht, 1993, pp. 99-112.

81 S. Şahin, E. A. Bleda, Z. Altun and C. Trindle, International Journal of Quantum Chemistry, 2016, 116, 444-451.

82 K. Watanabe, T. Nakayama and J. Mottl, Journal of Quantitative Spectroscopy and Radiative Transfer, 1962, 2, 369 - 382.

83 J. Pitarch-Ruiz, A. Sánchez de Merás, J. Sánchez-Marán, A. M. Velasco, C. Laván and I. Martán, The Journal of Physical Chem- istry A, 2008, 112, 3275-3280.

84 D. Truch, D. Salomon and D. Armstrong, Journal of Molecular Spectroscopy, 1979, 78, $31-39$.

85 T. J. Lee, J. E. Rice, G. E. Scuseria and H. F. Schaefer, Theoretica chimica acta, 1989, 75, 81-98.

86 D. C. Moule and A. D. Walsh, Chemical Reviews, 1975, 75, 67-84.

87 M. Mühlhäuser and M. Gruber-Stadler, Chemical Physics, 2008, 343, $311-318$.

88 H. G. Libuda, F. Zabel, E. H. Fink and K. H. Becker, The Journal of Physical Chemistry, 1990, 94, 5860-5865. 